\title{
Star Polymers Reduce Islet Amyloid Polypeptide Toxicity via Accelerated Amyloid Aggregation
}

Emily H. Pilkington, ${ }^{\dagger}$ May Lai, ${ }^{\dagger}$ Xinwei Ge, ${ }^{\dagger}$ William J. Stanley, ${ }^{\text {IL } \S}$ Bo Wang, ${ }^{\ddagger}$ Miaoyi Wang, ${ }^{\dagger}$ Aleksandr Kakinen, ${ }^{\dagger}$ Marc-Antonie Sani, ${ }^{\#}$ Michael R. Whittaker, ${ }^{\dagger}{ }^{\dagger}$ Esteban N. Gurzov, ${ }^{\mathrm{II}}{ }^{\S} \odot$ Feng Ding, John F. Quinn, ${ }^{*} \dagger \odot$ Thomas P. Davis, ${ }^{*},, \|_{\odot}$ and Pu Chun Ke ${ }^{*}+\odot$

${ }^{\dagger}$ ARC Centre of Excellence in Convergent Bio-Nano Science and Technology, Monash Institute of Pharmaceutical Sciences, Monash University, 381 Royal Parade, Parkville, Victoria 3052, Australia

${ }^{\ddagger}$ Department of Physics and Astronomy, Clemson University, Clemson, South Carolina 29634, United States

IISt Vincent's Institute of Medical Research, 9 Princes Street, Fitzroy, Victoria 3065, Australia

${ }^{\S}$ Department of Medicine, St. Vincent's Hospital, The University of Melbourne, Melbourne, Australia

${ }^{\#}$ School of Chemistry, Bio21 Institute, The University of Melbourne, 30 Flemington Rd, Parkville, Victoria 3010, Australia

"Department of Chemistry, University of Warwick, Gibbet Hill, Coventry CV4 7AL, United Kingdom

Supporting Information

ABSTRACT: Protein aggregation into amyloid fibrils is a ubiquitous phenomenon across the spectrum of neurodegenerative disorders and type 2 diabetes. A common strategy against amyloidogenesis is to minimize the populations of toxic oligomers and protofibrils by inhibiting protein aggregation with small molecules or nanoparticles. However, melanin synthesis in nature is realized by accelerated protein fibrillation to circumvent accumulation of toxic intermediates.

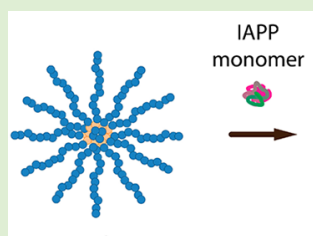

Star polymer

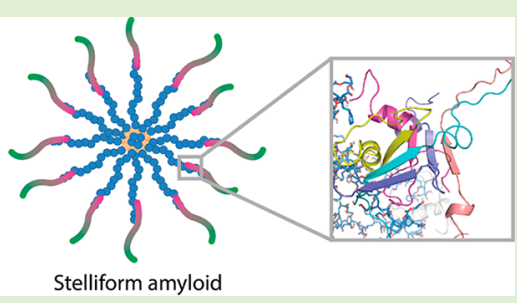
Accordingly, we designed and demonstrated the use of starshaped poly(2-hydroxyethyl acrylate) (PHEA) nanostructures for promoting aggregation while ameliorating the toxicity of human islet amyloid polypeptide (IAPP), the peptide involved in glycemic control and the pathology of type 2 diabetes. The binding of PHEA elevated the $\beta$-sheet content in IAPP aggregates while rendering a new morphology of "stelliform" amyloids originating from the polymers. Atomistic molecular dynamics simulations revealed that the PHEA arms served as rodlike scaffolds for IAPP binding and subsequently accelerated IAPP aggregation by increased local peptide concentration. The tertiary structure of the star nanoparticles was found to be essential for driving the specific interactions required to impel the accelerated IAPP aggregation. This study sheds new light on the structure-toxicity relationship of IAPP and points to the potential of exploiting star polymers as a new class of therapeutic agents against amyloidogenesis.

\section{INTRODUCTION}

Type 2 diabetes mellitus (T2D) is a metabolic disease affecting $5 \%$ of the global population. ${ }^{1}$ Extensive research indicates that a major factor in the development and pathogenesis of T2D is dysfunction of human islet amyloid polypeptide (IAPP), a $37-$ residue peptide cosecreted with insulin from pancreatic $\beta$-cells, which undergoes fibrillization to form amyloid plaques found in $90 \%$ of T2D patients. ${ }^{2,3}$ The toxic IAPP aggregation products are also capable of eliciting systemic damage in T2D patients with evidence of cardiac dysfunction and neurological deficits mediated by IAPP deposition increasing the burden of disease. ${ }^{4,5}$ Concordantly, there is a crucial need for the development of treatment agents that are capable of mitigating IAPP-associated toxicity in vivo to reduce the morbidity of T2D and prevent its development in prediabetics.

Aggregation inhibition with the use of small molecules as well as metal, carbon, and polymeric nanoparticles (NPs) ${ }^{6-9}$ has been a major strategy against amyloid-mediated toxicity.
Polymeric NPs, specifically, have been explored as protein aggregation inhibitors utilizing their tunable hydrophobicity as well as their capacity for initiating H-bonding. ${ }^{10-13}$ For example, antiprion activity has been demonstrated by phosphorus dendrimers, maltose-based glycodendrimers (mPPI), poly(propyleneimine) PPI, and poly(ethylenimine) hyperbranched polymers. ${ }^{12-20}$ Of the myriad forms of polymeric NPs, hyperbranched polymers and dendrimers have demonstrated strong efficacies as antiamyloid agents, ${ }^{11,12,15,21-26}$ though anti-IAPP applications have only been explored recently. PPI glycodendrimers and lysine dendrimers have been investigated as anti-A $\beta$ aggregation agents, $^{22,23}$ and hyperbranched PEG-based polymers with a dopamine moiety were found to be capable of inhibiting $\alpha$ -

Received: September 8, 2017

Revised: October 13, 2017

Published: October 16, 2017 
synuclein $(\alpha S)$ aggregation. ${ }^{11}$ Anionic low-generation dendrimers have been shown to modulate IAPP fibrillization and associated toxicity, ${ }^{24}$ and inhibition of IAPP fibrillization and toxicity in vitro and ex vivo has recently been demonstrated by our team with $\mathrm{OH}$-terminated polyamidoamine dendrimers (PAMAM-OH). ${ }^{26}$

Curiously, the amyloidogenesis of melanocyte protein Pmel17 in the human system is entirely nonpathogenic. ${ }^{27}$ The rapid fibrillization of Pmel17, which transitions from monomeric form to mature amyloid fibrils within $3 \mathrm{~s}$, is a cytoprotective mechanism, namely, through reducing the halflife of toxic intermediate products (i.e., oligomers and protofibrils) to favor the formation of nontoxic, mature amyloid fibrils. Indeed, this effect has been shown to extend to pathogenic amyloids; mice overexpressing the Alzheimer'srelated amyloidogenic peptide amyloid- $\beta(\mathrm{A} \beta)$ with the "Artic" mutation, correlated with the acceleration of $\mathrm{A} \beta$ fibrillization, demonstrated higher plaque loading with lower or negligible impact on behavioral function comparable to mice expressing wild-type $\mathrm{A} \beta .^{28}$ The concept of fibrillization promotion, rather than inhibition, thus provides a biomimetic and perhaps counterintuitive strategy in the mitigation of amyloid cytotoxicity.

Amyloid aggregation promotion as a strategy for mitigating cytotoxicity has thus far only been reported for a selected few small molecules. ${ }^{29,30}$ Specifically, high-throughput screening identified aromatic small molecules capable of promoting $\mathrm{A} \beta$ fibrillization to provide a cytoprotective effect, including the orcein-related molecule $\mathrm{O} 4^{30}$ and the compound 2002-H20. ${ }^{29}$ Small molecules, however, are imperfectly suited as antiamyloid agents when utilized without modifications to confer targeting specificity, as they frequently display molecular promiscuity. ${ }^{31}$

In this study, we synthesized and demonstrated the use of poly(2-hydroxyethyl acrylate) (PHEA) star polymers ${ }^{32}$ as an anti-IAPP agent capable of cytoprotective rescue of pancreatic $\beta$-cells through the promotion of amyloid aggregation. PHEA stars were synthesized using a reversible addition-fragmentation chain-transfer (RAFT) polymerization methodology and were designed to mimic the chemistry of small molecule aggregation promoters through the incorporation of hydroxyls and aromatic rings via the RAFT end-groups. ${ }^{33,34}$ The PHEA stars were weakly negatively charged, each possessing a hydrodynamic size of $\sim 12 \mathrm{~nm}$ and containing on average 12 arms. Through biophysical characterizations, we demonstrated a significant, positive correlation between amyloid aggregation promotion induced by PHEA stars and reduction in IAPP-mediated cytotoxicity both in vitro and ex vivo and additionally identified a new amyloid morphology, named "stelliform amyloids", formed by coaggregation of IAPP and PHEA stars at a molar ratio of 5:1. Atomistic discrete molecular dynamics (DMD) ${ }^{35}$ simulations revealed that the PHEA stars possessed rigid arms different from the porous and micellar PAMAM dendrimers. The rodlike arms served as linear scaffolds for IAPP binding and further accelerated the nucleation of $\beta$-sheet aggregates by increased local peptide concentration. Each arm of the PHEA stars could nucleate the fibrillization of IAPP resulting in the stelliform amyloid morphology. This study opens the door to the design and application of a new class of agents against amyloid diseases.

\section{EXPERIMENTAL METHODS}

Materials. 2-Hydroxyethyl acrylate (HEA) was purchased from Sigma-Aldrich and deinhibited by passing through a column of basic alumina. $S, S^{\prime}$-Dibenzyl trithiocarbonate (DBTC), $N, N^{\prime}$-methylenebis(acrylamide) (X) was purchased from Sigma-Aldrich. Azobis(isobutyronitrile) (AIBN) was purified by recrystallization from methanol before use. Dimethyl sulfoxide (DMSO) was purchased from Merck Millipore and used as received. Human islet amyloid polypeptide monomers (IAPP; disulfide bridge: 2-7; MW: 3,906; 37 residue: KCNTATCATQRLANFLVHSSNNFGAILSSTNVGSNTY; $>95 \%$ pure by HPLC) were obtained in lyophilized powder form from AnaSpec and were made up to a $200 \mu \mathrm{M}$ stock immediately prior to an experiment or allowed to fibrillate at $25{ }^{\circ} \mathrm{C}$ for $>5$ days to produce mature IAPP amyloids. All materials were weighed out on a Cubis MSE balance (Sartorius, $0.01 \mathrm{mg}$ resolution) and made up fresh in Milli-Q water prior to experiments unless otherwise specified. Thioflavin $\mathrm{T}(\mathrm{ThT})$ dye (Sigma-Aldrich) was prepared fresh for each experiment at a $250 \mu \mathrm{M}$ stock solution. Propidium iodide (PI) dye stock solution $\left(1 \mathrm{mg} / \mathrm{mL}\right.$ in water) was stored at $-20{ }^{\circ} \mathrm{C}$.

RAFT Synthesis of Poly(2-hydroxyl ethyl acrylate) Stars. Synthesis of Poly(2-hydroxyl ethyl acrylate) ( $p(H E A))$ Homopolymer. Three homopolymers of PHEA were prepared by RAFT polymerization with molecular weights of $4,000,8,000$, and $16000 \mathrm{~g} /$ mol.

The synthesis of PHEA $1\left(M_{\mathrm{n}}=4000 \mathrm{~g} / \mathrm{mol}\right)$ was carried out using the following stoichiometry: [DBTC]:[HEA]:[AIBN] $=1: 38: 0.1$. In brief, 2-hydroxyethyl acrylate $(4.00 \mathrm{~g}, 0.034 \mathrm{~mol})$, DBTC RAFT agent $\left(0.27 \mathrm{~g}, 9.12 \times 10^{-4} \mathrm{~mol}\right)$, AIBN $\left(15.4 \times 10^{-3} \mathrm{~g}, 9.38 \times 10^{-5} \mathrm{~mol}\right)$, and DMSO $(26 \mathrm{~mL})$ were placed into a $50 \mathrm{~mL}$ round-bottom flask equipped with a magnetic stirrer bar and capped with a rubber septum. The reaction mixture was deoxygenated for $1 \mathrm{~h}$ at $0{ }^{\circ} \mathrm{C}$ with nitrogen gas. The sealed deoxygenated reaction vessel was placed in a preheated oil bath at $70{ }^{\circ} \mathrm{C}$, and the polymerization was carried for $4 \mathrm{~h}$ with stirring. Polymerization was stopped by placing the vessel in ice to cool. The product was analyzed by ${ }^{1} \mathrm{H}$ NMR and GPC. The monomer conversion was determined to be approximately $88 \%$ by NMR, thus resulting in a $M_{\mathrm{w}}$ of $4141 \mathrm{~g} / \mathrm{mol}$. By integrating the peaks associated with the benzyl group (7.1-7.4 ppm) and the hydroxyl group in the PHEA repeat unit $(\delta=4.8 \mathrm{ppm})$, the $M_{\mathrm{n}(\mathrm{NMR})}$ is found to be $4374 \mathrm{~g} /$ mol. Per arm, there are 32 units of the PHEA monomer because the homopolymer constitutes 64 units. The molecular number and polydispersity index were determined by GPC to be $8,276 M_{n}$ and 1.30 , respectively.

A similar procedure was employed for the synthesis of PHEA $2\left(M_{\mathrm{n}}\right.$ $=8000 \mathrm{~g} / \mathrm{mol})$ using the following stoichiometry: [DBTC]:[HEA]: $[\mathrm{AIBN}]=1: 75: 0.1$. In brief, 2-hydroxyethyl acrylate $(4.00 \mathrm{~g}, 0.034$ mol), DBTC RAFT agent $\left(0.13 \mathrm{~g}, 4.58 \times 10^{-4} \mathrm{~mol}\right)$, AIBN $(7.2 \times$ $\left.10^{-3} \mathrm{~g}, 4.38 \times 10^{-5} \mathrm{~mol}\right)$, and DMSO $(26 \mathrm{~mL})$ were placed into a 50 $\mathrm{mL}$ round-bottom flask equipped with a magnetic stirrer bar and capped with a rubber septum. The reaction mixture was deoxygenated for $1 \mathrm{~h}$ at $0{ }^{\circ} \mathrm{C}$ with nitrogen gas. The sealed deoxygenated reaction vessel was placed in a preheated oil bath at $70{ }^{\circ} \mathrm{C}$, and the polymerization was carried for $4 \mathrm{~h}$ with stirring. Polymerization was stopped by placing the vessel in ice to cool. The product was analyzed by ${ }^{1} \mathrm{H}$ NMR and GPC. The monomer conversion was determined to be approximately $85 \%$ by NMR, thus resulting in an $M_{\mathrm{n}(\mathrm{th})}$ of $7716 \mathrm{~g} /$ mol. By integrating the peaks associated with the benzyl group (7.1$7.4 \mathrm{ppm})$ and the hydroxyl group in the PHEA repeat unit $(\delta=4.8$ ppm), the $M_{\mathrm{n}(\mathrm{NMR})}$ is found to be $7729 \mathrm{~g} / \mathrm{mol}$. Per arm, there are 32 units of the PHEA monomer; therefore, the homopolymer constitutes 64 units. The molecular number and polydispersity index were determined by GPC to be $14,688 M_{\mathrm{n}}$ and 1.24 , respectively.

The synthesis of PHEA $3\left(M_{\mathrm{n}}=16,000 \mathrm{~g} / \mathrm{mol}\right)$ was achieved in a similar method as above using the following stoichiometry: [DBTC]: $[\mathrm{HEA}]:[\mathrm{AIBN}]=1: 144: 0.1$. In brief, 2-hydroxyethyl acrylate (4.91 g, $0.042 \mathrm{~mol})$, DBTC RAFT agent $\left(0.085 \mathrm{~g}, 2.93 \times 10^{-4} \mathrm{~mol}\right)$, AIBN (5 $\left.\times 10^{-3} \mathrm{~g}, 3.04 \times 10^{-5} \mathrm{~mol}\right)$, and DMSO $(32 \mathrm{~mL})$ were placed into a $50 \mathrm{~mL}$ round-bottom flask equipped with a magnetic stirrer bar and capped with a rubber septum. The reaction mixture was deoxygenated for $1 \mathrm{~h}$ at $0{ }^{\circ} \mathrm{C}$ with nitrogen gas. The sealed deoxygenated reaction vessel was placed in a preheated oil bath at $70{ }^{\circ} \mathrm{C}$ and the polymerization was carried for $6 \mathrm{~h}$ with stirring. Polymerization was terminated by placing the vessel in ice to cool. The product was 
analyzed by ${ }^{1} \mathrm{H}$ NMR and GPC. The monomer conversion was determined to be approximately $91 \%$ by NMR, thus resulting in an $M_{w}$ of $15,553 \mathrm{~g} / \mathrm{mol}$. By integrating the peaks associated with the benzyl group (7.1-7.4 ppm) and the hydroxyl group in the PHEA repeat unit ( $\delta=4.8 \mathrm{ppm})$, the $M_{\mathrm{n}(\mathrm{NMR})}$ is found to be $15,961 \mathrm{~g} / \mathrm{mol}$. The molecular number and polydispersity index were determined by GPC to be $26,676 M_{\mathrm{n}}$ and 1.24 , respectively.

Synthesis of PHEA Star. A typical PHEA star synthesis is carried out as follows. The synthesis of PHEA star was conducted using the following stoichiometry: [PHEA 2]:[HEA]:[AIBN]:[XL] = 1:12:0.4:18. In brief, a $1.86 \mathrm{~mL}$ aliquot ( $250 \mathrm{mg}$ equivalent) of the solution above, AIBN $\left(1.60 \mathrm{mg}, 9.76 \times 10^{-3} \mathrm{~mol}\right)$, methylene bis(acrylamide) (77.09 mg, $0.5 \mathrm{~mol}$ ), and $930 \mu \mathrm{L}$ of DMSO were added into a glass vial equipped with a magnetic stirrer bar and capped with a rubber septum. The reaction mixture was deoxygenated for 30 min at $0{ }^{\circ} \mathrm{C}$ with nitrogen gas. The sealed deoxygenated reaction vessel was placed in a preheated oil bath at $70{ }^{\circ} \mathrm{C}$, and the polymerization was carried for $24 \mathrm{~h}$ with stirring. Polymerization was terminated by placing the vessel in ice to cool.

Purification was conducted by dialysis against water with a MWCO of $14 \mathrm{kDa}$ for 2 days and then lyophilization. The product was analyzed by GPC, and its molecular number and polydispersity index were determined to be $85,500 M_{\mathrm{n}}$ and 2.18 , respectively. With the given $M_{\mathrm{n}}$ values from GPC, the star was calculated to have 12 arms. In theory, the molecular weight of the star is $47,295 \mathrm{~g} / \mathrm{mol}$.

Analysis Methods. ${ }^{1} \mathrm{H}$ Nuclear Magnetic Resonance Spectroscopy. ${ }^{1} \mathrm{H}$ NMR spectra were recorded at $400 \mathrm{MHz}$ on a Bruker UltraShield $400 \mathrm{MHz}$ spectrometer running Bruker Topspin, version 1.3. Spectra were recorded in DMSO- $d_{6}$.

Gel Permeation Chromatography (GPC). GPC was performed using a Shimadzu modular system comprised of a SIL-20AD automatic injector, a RID-10A differential refractive-index detector, and a $50 \times$ $7.8 \mathrm{~mm}$ guard column followed by three KF-805L columns $(300 \times 8$ $\mathrm{mm}$, bead size: $10 \mu \mathrm{m}$, pore size maximum: $5000 \AA$ ). $N, N^{\prime}$ -Dimethylacetamide (DMAc, HPLC grade, $0.03 \% \mathrm{w} / \mathrm{v} \mathrm{LiBr}$ ) at 50 ${ }^{\circ} \mathrm{C}$ was used for the analysis with a flow rate of $1 \mathrm{~mL} \mathrm{~min}{ }^{-1}$. Samples were filtered through $0.45 \mu \mathrm{m}$ PTFE filters before injection. The GPC calibration was performed with narrow-polydispersity polystyrene standards ranging from 500 to $2 \times 10^{6} \mathrm{~g} \mathrm{~mol}^{-1}$.

Dynamic Light Scattering (DLS). DLS was carried out on a Malvern Zetasizer Nano ZS Series running DTS software (laser, 4 $\mathrm{mW}, \lambda=633$; angle $173^{\circ}$ ). The polydispersity index (PDI) used to describe the average diameters and size distribution of prepared stars was determined via a cumulants analysis of the measured intensity autocorrelation function using the DTS software. Samples were filtered using $0.45 \mu \mathrm{m}$ PTFE syringe filter to remove contaminants/dust prior to the measurement.

Fourier Transform Infrared Spectroscopy-Attenuated Total Reflectance (FTIR-ATR). ATR-FTIR measurements were performed using a Shimadzu IRTracer 100 Fourier transform infrared spectrometer with a GladiATR 10 single reflection ATR accessory. Spectra were obtained in the midinfrared region of $4000-600 \mathrm{~cm}^{-1}$ at a resolution of $8 \mathrm{~cm}^{-1}$ (512 scans) and analyzed using LabSolution IR software.

Thioflavin T Assay. Aliquots of IAPP (final concentration of 25 $\mu \mathrm{M})$, ThT dye $(25 \mu \mathrm{M})$, and PHEA polymers $(5,1$, or $0.2 \mu \mathrm{M})$ were added directly to wells of a black/clear bottom 96-well plate (Costar) and mixed thoroughly. The final well volume of $100 \mu \mathrm{L}$ was made up using Milli- $Q$ water where necessary. The plate was run on a Flexstation 3 plate reader (Molecular Devices) with samples excited at $440 \mathrm{~nm}$ and the emission read at $485 \mathrm{~nm}$ every $5 \mathrm{~min}$ for a total of 14 h (169 readings).

Circular Dichroism (CD) Spectroscopy. Experiments were performed on a Chirascan CD spectrometer (Applied Photophysics) with spectra read from 190 to $260 \mathrm{~nm}$. Prior to sample loading, a baseline with no cuvette was run. Then, $300 \mu \mathrm{L}$ of $25 \mu \mathrm{M}$ IAPP in Milli-Q water alone or in the presence of PHEA $(5 \mu \mathrm{M})$, was placed in a cuvette with a $0.1 \mathrm{~cm}$ path length, and $\mathrm{CD}$ analysis was run at $0,2.5$, and $24 \mathrm{~h}$ time points. Between samples, cuvettes were washed more than $5 \times$ with distilled water. Reads are an average of 3 repeats. Raw data were offset to zero and normalized against the spectra of Milli- $Q$ water for IAPP spectra and against PHEA alone for IAPP-PHEA mixed samples. Data were then deconvoluted with CDNN software to give a final relative percentage content of secondary structure.

Transmission Electron Microscopy. Samples were placed in Eppendorf tubes at a final IAPP concentration of $25 \mu \mathrm{M}$ and incubated for $24 \mathrm{~h}$ at $25{ }^{\circ} \mathrm{C}$. An aliquot $(10 \mu \mathrm{L})$ was placed on 400 mesh carbon-coated Formvar copper grids (ProSciTech) that were glow-discharged to promote hydrophilicity. Samples were adsorbed onto the grid for $60 \mathrm{~s}$, then drawn off using filter paper. Grids were washed twice with $10 \mu \mathrm{L}$ of Milli-Q water. Five microliters of $1 \%$ uranyl acetate (in water) was then utilized to twice-stain grids by touching one droplet and immediately drawing the stain off, and then placing the grid atop the second droplet to stain for $15 \mathrm{~s}$. TEM images were obtained on a Tecnai TF20 transmission electron microscope (FEI) with an UltraScan $1000(2 \mathrm{k} \times 2 \mathrm{k})$ CCD camera (Gatan).

Determination of Fibril Morphology. Fibril tracking and analysis were performed with software FiberApp ${ }^{36}$ to determine the morphology and mesoscopic parameters of persistence length $(\lambda)$ and contour length $(l)$ of IAPP fibrils. FiberApp was developed from statistical physics and enables structural analysis of tubular and macromolecular objects. The persistence length $\lambda$ reflects the stiffness of a polymer and is mathematically defined via the bond correlation function (BCF) in $3 \mathrm{D}$ or $2 \mathrm{D}$ as the length over which angular correlations in the tangential direction decrease by a factor of $e e^{37}$ Here, the $\lambda$ values of IAPP fibrils were estimated using the BCF, meansquared end-to-end distance (MSED), and mean-squared midpoint displacement (MSMD) methods and presented as averaged values determined by the three methods. The contour length corresponds to the end-to-end length of a polymer along its physical contour. The values of persistence length and contour length were obtained based on statistical analysis of 1,243 fibrils.

Cell Culture and Viability. Insulin-producing $\beta$ TC6 cells (ATCC) were cultured in complete DMEM (ATCC; 15\% FBS). For viability assays, a 96-well plate (Corning) was coated with $70 \mu \mathrm{L}$ of $70 \mu \mathrm{g} / \mathrm{mL}$ poly-D-lysine for $>10 \mathrm{~min}$; then, the wells were washed $3 \times$ in $100 \mu \mathrm{L}$ of HBSS. Cells were seeded at a density of $\sim 50,000$ cells per well in $200 \mu \mathrm{L}$ of complete media and incubated at $37{ }^{\circ} \mathrm{C}$ in $5 \% \mathrm{CO}_{2}$ for 3 days. Fresh IAPP or mature IAPP amyloids $(200 \mu \mathrm{M}$ stock $)$ were preincubated together with PHEA polymers (40, 8, and $3.2 \mu \mathrm{M}$ stocks) at a $1: 1 \mathrm{v} / \mathrm{v}$ ratio for $24 \mathrm{~h}$ at room temperature. Prior to cell treatment, the media was aspirated, and the wells were washed $1 \times$ in $100 \mu \mathrm{L}$ of HBSS. One micromolar propidium iodide (PI; AnaSpec) dye solution was made up in complete media containing $1 \%$ penicillin/ streptomycin, and $150 \mu \mathrm{L}$ aliquots were added to each of the wells. The cells were returned to the incubator for $30 \mathrm{~min}$ to equilibrate with the dye solution. Each sample treatment was then added to the wells in triplicate, in addition to an IAPP control made up fresh immediately prior to adding to the wells (final well volume: $200 \mu \mathrm{L}$; final IAPP concentration: $25 \mu \mathrm{M}$ ). The cells were imaged on an Operetta HighContent Imaging System (PerkinElmer) utilizing standardized excitation/emission settings for PI with images of five areas within a single well taken every hour for $24 \mathrm{~h}$. Total cell counts per well were estimated using phase-contrast mapping within sampling areas. Cell death over time was expressed as \%PI positive cells within the total cell count.

Ex Vivo Viability. C57BL/6 male mice (age 10-14-week-old) were maintained at St. Vincent's Institute animal care facility on a $12 \mathrm{~h}$ lightdark cycle in a temperature-controlled room and obtained food and water ad libitum. Uniformly sized mouse islets from C57BL/6 mice were handpicked into $1 \mathrm{~cm}$ Petri dishes containing $1 \mathrm{~mL}$ of $25 \mu \mathrm{M}$ hIAPP, $5 \mu \mathrm{M}$ PHEA, or a combination of both and cultured for $48 \mathrm{~h}$. At the end of the culture period, islets were dispersed with trypsin and resuspended in $250 \mu \mathrm{L}$ of hypotonic buffer containing $50 \mu \mathrm{g} / \mathrm{mL}$ of propidium iodide, which stained nuclear DNA. The cells were analyzed by fluorescence-activated cell sorter (FACS), and cell death was identified by their subdiploid DNA content as previously described. ${ }^{38}$ The study was conducted at St Vincent's Institute (Melbourne, Australia) following the guidelines of the Institutional Animal Ethics Committee. 
A Arm synthesis:<smiles>C=CC(=O)OCCO</smiles>

Star formation (six-armed as indicated):

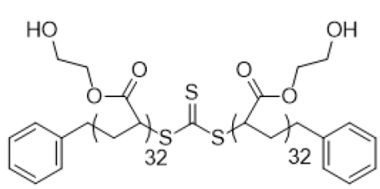<smiles>C=CC(=O)NCNC(=O)C=C</smiles>
AlBN, DMSO, 24 hours, $70^{\circ} \mathrm{C}$ $\approx \stackrel{\mathrm{O}}{\mathrm{O}} \mathrm{\sim OH}$

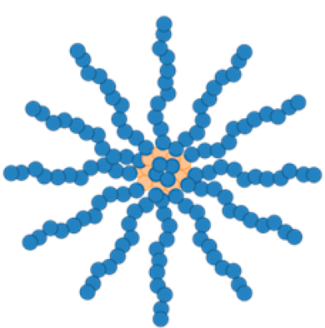

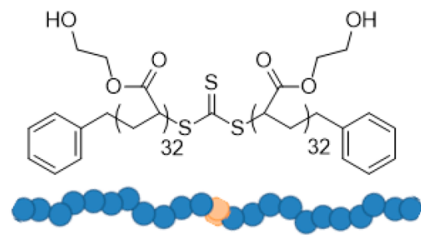

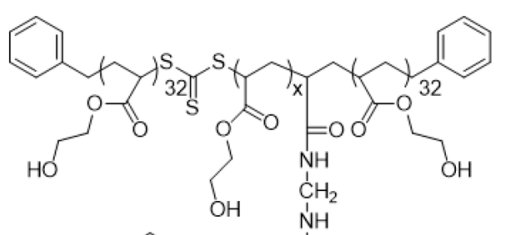

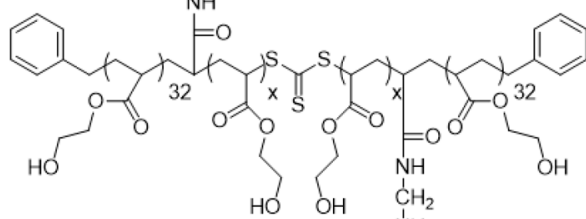
NH

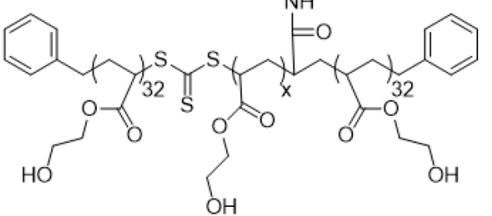

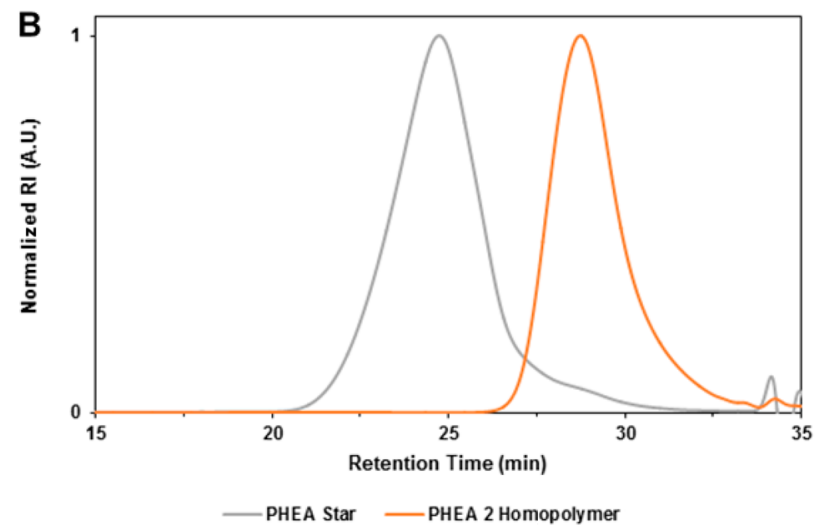

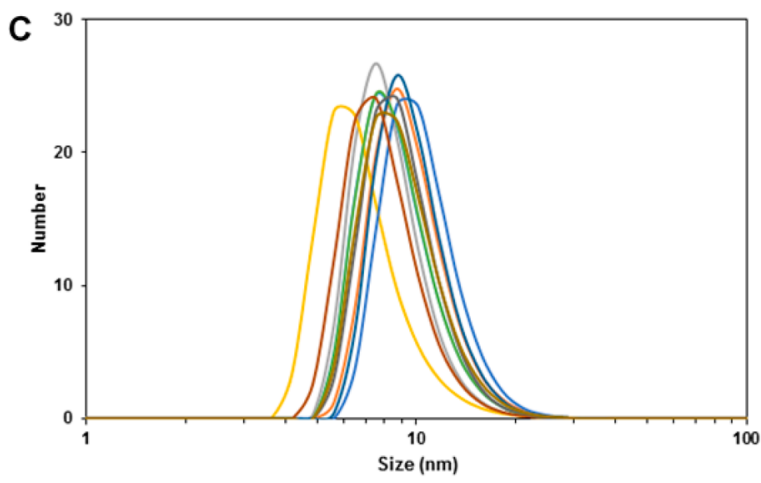

Figure 1. Synthesis and preliminary characterization of PHEA stars via RAFT polymerization. (A) Synthesis of PHEA stars using a symmetrical RAFT agent. (B) Gel permeation chromatograms for the PHEA arm (orange) and star (gray). (C) Size distribution by number from dynamic light scattering for PHEA stars.

Statistics. Where applicable, data were analyzed using a one-way ANOVA with Tukey's correction with $p<0.05$ considered statistically significant.

DMD Simulations and Simulation Setup. DMD is a special form of molecular dynamics, where discrete step functions instead of continuous functions are used to mimic the constraints. The unitedatom representation with all polar hydrogen and heavy atoms was used to model IAPPs and PHEA polymers. An adapted Medusa force field ${ }^{35}$ with an implicit solvent model was used to describe the nonbonded interatomic interactions, including van der Waals, solvation, hydrogen bonding, and electrostatic terms. The Debye-Hückel approximation with a Debye length of $\sim 10 \AA$ was applied to capture the screened electrostatic interactions. Anderson's thermostat was used to maintain temperature, which was fixed at $300 \mathrm{~K}$ in all simulations. The DMD program is freely available to academic users at the Molecules in Action Web site (http://moleculesinaction.com), and all simulation parameters can be obtained upon request. Given the stochastic nature in the dynamics of a multimolecular system and the nucleationdependent aggregation kinetics, we performed multiple independent long simulations with different starting configurations (e.g., random- ized velocities, intermolecular distances and orientations) to ensure sufficient sampling and avoid potential bias associated with initial configurations. Thermodynamic and kinetic prosperities were then obtained by analyzing all the independent runs for each molecular system.

All the PHEA model structures were constructed with the Avogadro $^{39}$ molecular builder software and energy minimized with the MMFF94s force field. ${ }^{40}$ MedusaScore, ${ }^{41}$ an extension of the Medusa force field, ${ }^{42}$ was adapted to model the polymers in addition to IAPP. The MedusaScore was parametrized on a large set of ligands and was transferrable to different molecular systems. The predictive power of MedusaScore has been validated in various benchmark studies, including recent community structure-activity resource (CSAR) blind ligand-receptor docking prediction exercises. ${ }^{43,44}$

For each 2-arm PHEA (Figure S3A), we performed 20 independent simulations at $300 \mathrm{~K}$ with different starting configurations. Each independent simulation lasted $300 \mathrm{~ns}$, and thus, an accumulative $6 \mu \mathrm{s}$ simulation was obtained for the polymer model. We used the last half of all simulations and computed the radius of gyration $\left(R_{\mathrm{g}}\right)$ values of the modeled polymers. For the 8-arm PHEA (Figure S3C), 20 
independent simulations were performed at $300 \mathrm{~K}$ with different starting configurations, each of which lasted $200 \mathrm{~ns}$.

The IAPP (PDB ID: 2L86) structure was obtained from PDB. Counterions $\mathrm{Cl}^{1-}$ were introduced to achieve a neutral charge condition if necessary. For systems containing six IAPPs (with and without a 6-arm PHEA as shown in Figure S3B), the peptide concentration was maintained by fixing the dimension of the simulation box as $120 \AA$, and periodic boundary conditions were applied. For each of the multimolecular systems, 20 independent simulations starting with different intermolecular distances and orientations were performed at $300 \mathrm{~K}$, and each run lasted $100 \mathrm{~ns}$.

Secondary structure analyses were performed using the dictionary secondary structure of protein (DSSP) method. For each snapshot structure, the secondary structure, such as helix, sheet, coil, and turn, for each residue was obtained. An empirical sigmoidal function

$$
y=\left(I_{\max }-I_{\min }\right) /\left(1+\exp \left(-k\left(t-t_{0}\right)\right)\right)+I_{\min }
$$

was adopted to fit the kinetics of the total number of residues in the $\beta$ sheet conformation, where fitting parameters $A, B, t_{0}$, and $k$ corresponded to the max and min values of aggregation, the midpoint time of aggregation, and the elongation rate, respectively. The lag time was determined as

$$
t_{\text {lag }}=t_{0}-2 / k
$$

In the potential of mean force (PMF) calculation, normalized sigmoidal function, $Q_{\text {fibrilization }}=1 /\left(1+\exp \left(-k\left(t-t_{0}\right)\right)\right)$, was used to quantify the extent of fibrillization for each independent simulation. For a given snapshot, the distribution of IAPP oligomers was analyzed, where any two peptides interconnected by at least one intermolecular heavy atom contact (the cutoff of $0.55 \mathrm{~nm}$ ) was defined to belong to an oligomer. The size of an oligomer, $n_{\text {oligomer, }}$ was defined by the number of IAPP peptides forming the aggregate. The two-dimensional PMF (or effective free energy) was computed according to

$$
\mathrm{PMF}=-K_{\mathrm{B}} T \ln P\left(n_{\text {oligomer }}, Q_{\text {fibrillization }}\right)
$$

where $K_{B}$ is the Boltzmann constant, $T$ corresponds to the simulation temperature $300 \mathrm{~K}$, and $P\left(n_{\text {oligomer }}, Q_{\text {fibrilization }}\right)$ is the probability of finding a peptide in an oligomer with the size of $n_{\text {oligomer }}$ and the extent of fibrillization $Q_{\text {fibrilization }}$ at the time.

\section{RESULTS AND DISCUSSION}

Synthesis and Characterization of PHEA Stars. PHEA stars were synthesized with constitutive elements similar to those observed in small molecule aggregation promoters. Specifically, the stars were designed to incorporate aromatic rings (on the distal end of the star arms) and pendant hydroxyls on the side chains of the arms. To actualize these design criteria, we chose $S, S^{\prime}$-dibenzyltrithiocarbonate (DBTC) as the RAFT agent and employed in the polymerization of 2hydroxethyl acrylate (Figure 1A). The polymerization was carried out in DMSO at $70{ }^{\circ} \mathrm{C}$ using AIBN as the radical initiator. To provide a suitable array of arm molecular weights for the subsequent star formation, we first synthesized three PHEA homopolymers with varying degrees of polymerization to approximately $80-90 \%$ conversion. The $M_{n}$ of the homopolymers was determined via ${ }^{1} \mathrm{H}$ NMR analysis by comparing integrals for the peaks at $\delta=7.1-7.4 \mathrm{ppm}$ (corresponding to the benzyl leaving group of the RAFT agent, i.e., the polymer end group) with the integral for the peak corresponding to the hydroxyl group in the PHEA repeat unit $(\delta=4.8 \mathrm{ppm})$. These results agreed well with the theoretical molecular weights determined from the ratio of the monomer to RAFT agent (see Table S1). GPC analysis of the various PHEA homopolymers revealed unimodal peaks with an acceptable dispersity of $1.2-1.3$, although of course the $M_{n}$ values from GPC differed considerably from those determined above due to calibration of the GPC against polystyrene standards.

The solutions of arm polymers (including unreacted HEA) were then used to form the PHEA stars by adding methylene(bis(acrylamide)) at various molar ratios and a further aliquot of AIBN and then heating at $70{ }^{\circ} \mathrm{C}$ for $24 \mathrm{~h}$. Samples were taken periodically during the reaction with a further aliquot of AIBN injected after $12 \mathrm{~h}$. A library of different core-cross-linked stars were formed with the results tabulated in Table S2. It is worth noting that the symmetrical nature of the RAFT agent used (DBTC) gave rise to arm polymer in which the thiocarbonylthio moiety was in the middle of the polymer chain. As such, subsequent introduction of the difunctional monomer (to facilitate formation of the cross-linked core) occurred in the middle of the arm polymer. The consequence of this architecture is that the final stars had an arm molecular weight that was half the value of the starting "arm" material. To our knowledge, this is the first time that this approach (i.e., the use of a symmetrical RAFT agent such as DBTC) has been employed in the preparation of star polymers. The resulting star polymers were analyzed by gel permeation chromatography to identify the best conditions for star formation. For all systems, there was a shift in the GPC trace for the PHEA homopolymer to shorter retention times, reflecting successful chain extension, with this shift typically most pronounced for higher ratios of cross-linker to polymer (Figure $1 \mathrm{~B}$; for $[\mathrm{P}]:[\mathrm{M}]:[\mathrm{X}]=1: 12: 16$ and $\left.M_{\mathrm{n}(\mathrm{GPC})}{ }^{\text {arm }}=14,500 \mathrm{~g} \mathrm{~mol}^{-1}\right)$. Estimation of approximate arm number could be made by dividing the $M_{\mathrm{n}(\mathrm{GPC})}$ for the star by $1 / 2 M_{\mathrm{n}(\mathrm{GPC})}$ for the arm. The factor of $1 / 2$ is introduced into this equation because of the symmetry of the chain transfer agent, as noted above. For each series, higher ratios of crosslinker led to higher arm numbers. It should be noted, however, that these values are only indicative of the true arm number due to the potential underestimation of molecular weight when applying GPC to hyperbranched materials. Moreover, the indicative nature of this approach is clearly evident in that the arm number should only ever be even given the symmetrical nature of the RAFT agent. Importantly, the use of DBTC as a RAFT agent for the HEA polymerization and the subsequent formation of star from DBTC-derived PHEA led to somewhat broader molecular weight distributions than have been achieved using other star polymer systems. ${ }^{33}$ Although there is evidence in the literature that varying the solvent for star formation can improve arm incorporation and minimize polydispersity, ${ }^{33}$ the scope for optimization of the current system was limited by the intransigent solubility of the stars in most solvents: we observed that the resulting materials were soluble only in DMSO or water. Even then, some difficulty was encountered when attempting to redisperse the star in these solvents after lyophilization. We attribute this effect to hydrogen bonding between the arms and as such allowed a minimum of $72 \mathrm{~h}$ for the polymer to equilibrate after redispersing in water.

From the GPC data, the star with the clearest shift to higher molecular weight accompanied by maintenance of a relatively unimodal molecular weight distribution was observed for the system where $M_{\mathrm{n}(\mathrm{GPC})}{ }^{\text {arm }}=14,500 \mathrm{~g} \mathrm{~mol}^{-1}$ and $[\mathrm{P}]:[\mathrm{M}]:[\mathrm{X}]=$ $1: 12: 16$. Analysis of this material by dynamic light scattering (Figure 1C) indicated a number-average hydrodynamic radius of approximately $9.8 \mathrm{~nm}$ for the stars when dispersed in water, which is consistent with other water-soluble star polymers synthesized via RAFT polymerization. Spectroscopic evaluation of these same PHEA stars was also conducted with the recorded ${ }^{1} \mathrm{H}$ NMR spectrum confirming that the desired 

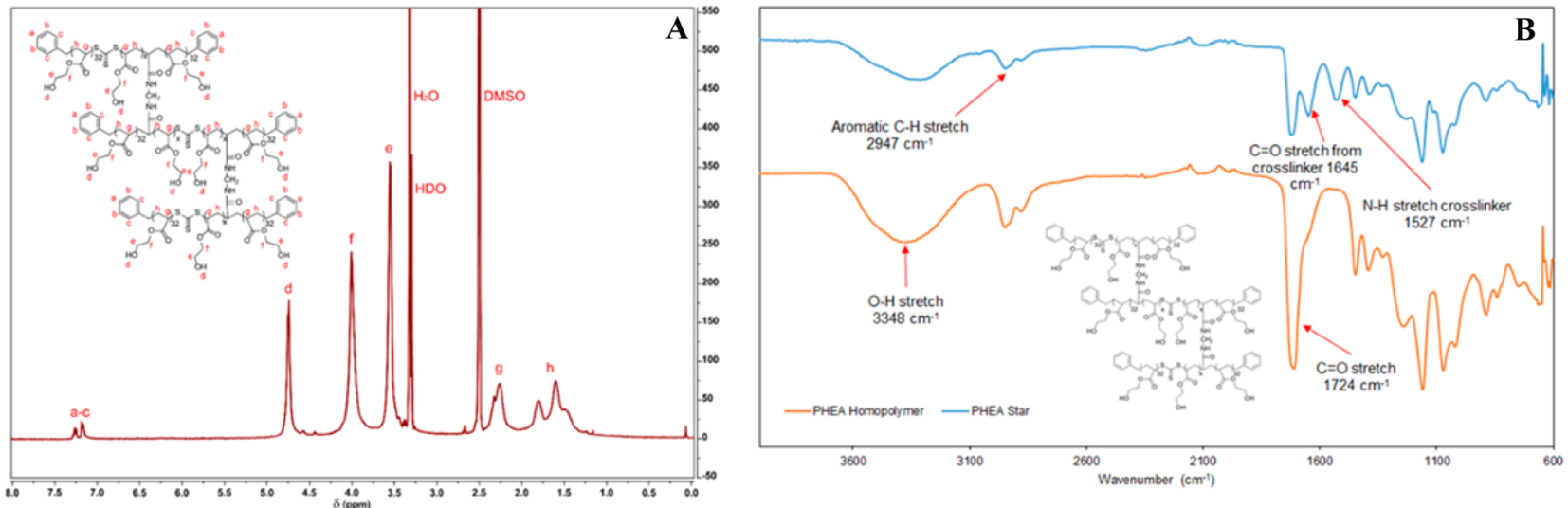

Figure 2. (A) ${ }^{1} \mathrm{H}$ NMR spectrum of purified PHEA stars recorded in DMSO- $d_{6}(400 \mathrm{MHz})$. The phenyl end-groups are evident at $\delta=7.2-7.3 \mathrm{ppm}$. (B) FTIR-ATR spectra for the PHEA arm (orange) and star (blue).
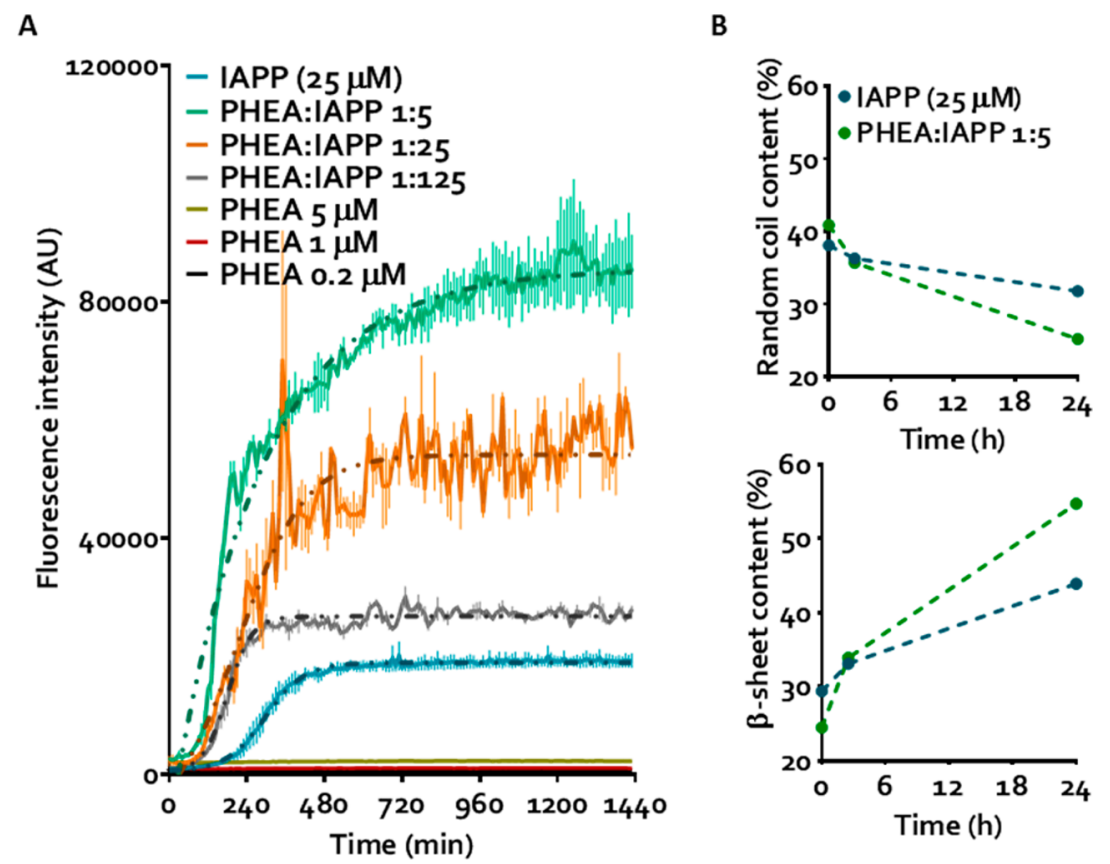

Figure 3. (A) ThT fluorescence of IAPP in the presence of PHEA stars over $24 \mathrm{~h}$. Dotted lines represent sigmoidal curve fitting (least-squares fit); error is SEM $(n=2)$. (B) Secondary structure transitions in IAPP mapped by circular dichroism at $0,2.5$, and $24 \mathrm{~h}$ time points. Lines are intended to guide the eye. The concentration of IAPP in all experiments is $25 \mu \mathrm{M}$.

aromatic and hydroxyl moieties were present in the final polymer structure (Figure 2A). FTIR analysis before and after star formation provided further evidence of the high proportion of $\mathrm{OH}$ groups in the star in addition to demonstrating the presence of the methylene(bis(acrylamide)) linking groups in the star core (Figure 2B). Specifically, the emergence of peaks associated with amide $\mathrm{C}=\mathrm{O}$ stretch $\left(1,645 \mathrm{~cm}^{-1}\right)$ and amide $\mathrm{N}-\mathrm{H}$ stretch $\left(1,547 \mathrm{~cm}^{-1}\right)$ provide clear evidence that the amide cross-linking groups were successfully incorporated into the star structure.

Modulation of IAPP Fibrillization by PHEA Polymers. The thioflavin $\mathrm{T}$ (ThT) assay utilizes the amyloidophilic ThT dye to provide a measurement of both the extent and kinetics of amyloid fibrillization over time. The control IAPP was shown to fibrillate with a nucleation period of $\sim 2 \mathrm{~h}$ followed by an exponential period of $\sim 12 \mathrm{~h}$ before reaching saturation at $14 \mathrm{~h}$ (Figure 3A). Incubation of PHEA with IAPP at molar concentrations of 1:5 and 1:25 had a promotional effect on
IAPP fibrillization both for the star NPs and their constituent subunits, referred to as "arms" (Figure S1), with the largest increase in ThT fluorescence observed at 1:5. Following the trend of increasing fibrillization with increasing concentration of PHEA, the energetically unfavorable nucleation period was also shown to significantly decrease with increasing concentration of PHEA, falling from $\sim 3.5 \mathrm{~h}$ in the IAPP control to less than 30 min with the highest concentration of PHEA. The reduction in IAPP lag time was also demonstrated through circular dichroism (CD) spectroscopy, wherein the presence of PHEA to IAPP at the $1: 5$ ratio notably promoted the amyloidogenic conversion of random coil content to $\beta$-sheets (Figures $3 \mathrm{~B}$ and Figure S3). Over $2.5 \mathrm{~h}, \beta$-sheet conversion in IAPP:PHEA 1:5 (25-34\%) was $2.3 \times$ more rapid than that of IAPP alone (29-33\%), and concordantly, IAPP contained $25 \%$ higher $\beta$-sheet content at $24 \mathrm{~h}$ in the presence of PHEA (55\%) compared to that of IAPP alone (44\%). This shift in prototypical IAPP aggregation kinetics, in addition to the 
A

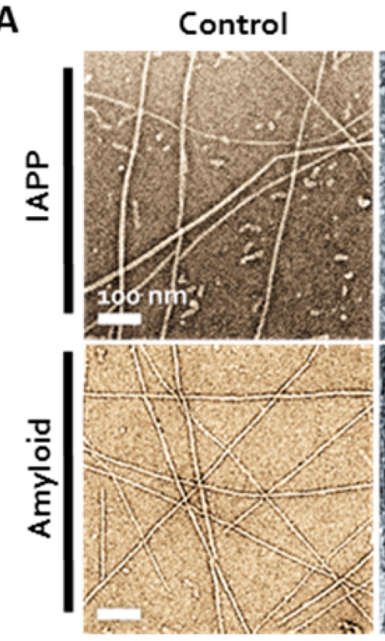

1:5

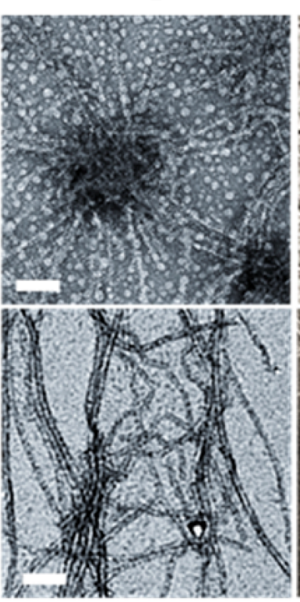

$1: 25$

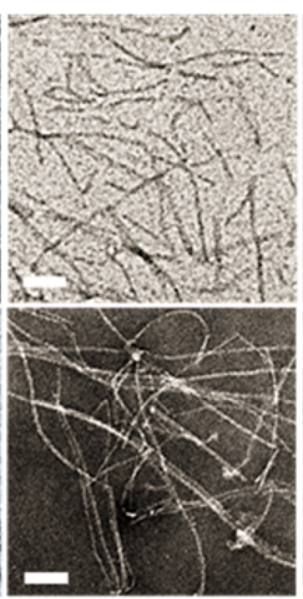

$1: 125$

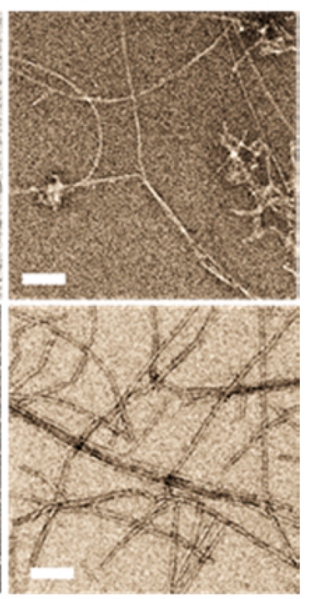

B
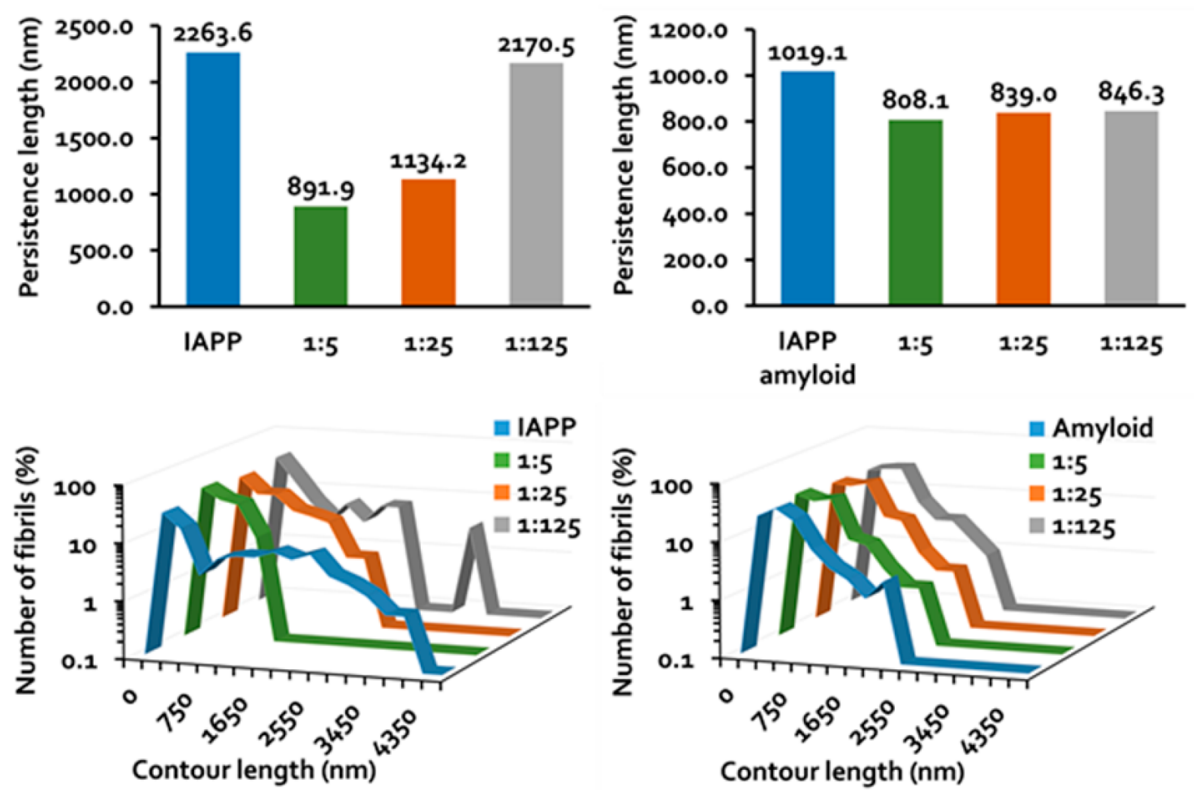

Figure 4. (A) TEM imaging of fibrillating IAPP (IAPP) and mature IAPP amyloids (Amyloid) in the presence and absence of PHEA stars after $24 \mathrm{~h}$ incubation. Stelliform amyloids are seen at PHEA:IAPP 1:5. Scale $=100 \mathrm{~nm}$. (B) Structural analysis of amyloid fibrils visualized in (A). IAPP concentration in all experiments is $25 \mu \mathrm{M}$.

promotion of fibrillization overall, presents a case for rapid local sequestration of IAPP seeds by PHEA, whereas a lower PHEA concentration ratio would isolate aggregation "hotspots" and thus limit fibril elongation but promote coaggregation and thus enhance fibrillization at higher PHEA concentrations.

Stelliform Amyloid Formation and Amyloid Remodeling by PHEA. Transmission electron microscopy (TEM) imaging complemented ThT and CD analyses for fibrillating IAPP, allowing further analysis of persistence and contour length of amyloid fibrils generated after $24 \mathrm{~h}$ in aqueous solution in the presence and absence of PHEA. After $24 \mathrm{~h}$, IAPP amyloidogenesis reached the saturation phase, and long, semiflexible fibrils can be observed by TEM with some shorter species still present (Figure 4A). Once fibril elongation and 3D cross-linking occurred at $>5$ days of amyloidogenesis, amyloids formed in-solution hydrogels, and generally, shorter species were absent. ${ }^{45}$ "Stelliform amyloids" were observed when PHEA was incubated with IAPP at a 1:5 molar ratio (Figure $4 \mathrm{~A})$. These amyloids were characterized by a central nucleation "core", ranging from smaller clusters of $50-150 \mathrm{~nm}$ to micrometers in diameter. Fibrils of low persistence (average of $891.9 \mathrm{~nm}$ compared with that of $2,885 \pm 60 \mathrm{~nm}$ for the IAPP control $\left.^{6,7}\right)$ and contour length $(<1,350 \mathrm{~nm})$ were additionally observed radiating out from the core, forming the full stelliform structure of $\sim 0.5 \mu \mathrm{m}$ in diameter for smaller cores and micrometers in diameter for larger cores with some macroscopic aggregates visible in solution (Figure 4A).

With lower concentrations of PHEA, the fibrillization products generally trended toward matching the structural morphology of IAPP alone (Figure 4B). IAPP amyloid fibrils with significantly reduced contour lengths were produced with increasing PHEA concentration, indicating polyphenol-like stabilization of growing fibrils through $\mathrm{H}$-bonding; hydrophobic and $\pi-\pi$ interactions by PHEA $^{46}$ may have terminated fibril elongation, resulting in a fibril population with predominantly low contour lengths. As fibril elongation is mediated by amyloid seeds, the extensive exponential periods observed in the ThT assay (Figure $3 \mathrm{~A}$ ) could be indicative of the PHEA-IAPP 
A
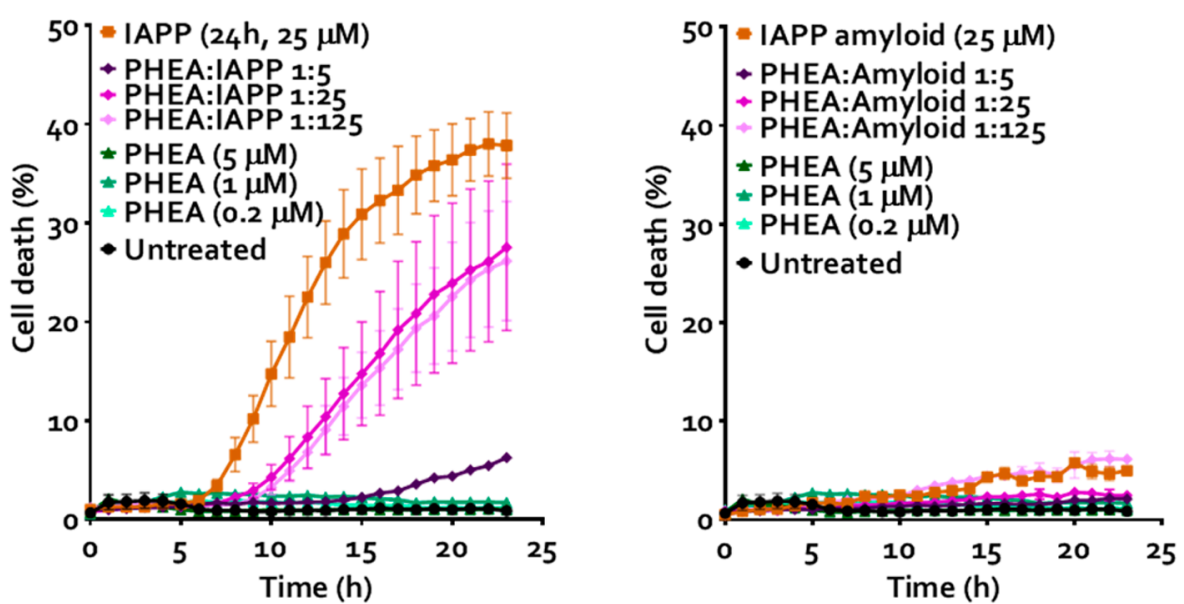

B
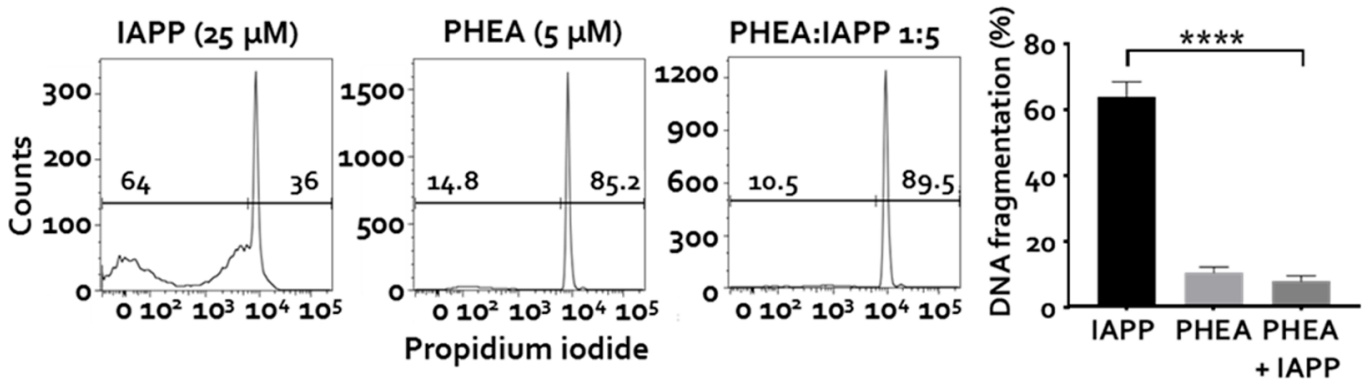

Figure 5. Protective effect of PHEA stars against IAPP-mediated cytotoxicity in pancreatic beta cells and islets. (A) In vitro cytotoxicity of fibrillating IAPP and mature IAPP amyloids in the presence and absence of PHEA in $\beta$ TC6 cells over $24 \mathrm{~h}$. Error $=$ SEM $(n=3)$. (B) Ex vivo cytotoxicity of fibrillating IAPP and IAPP:PHEA at a 1:5 molar ratio in mouse islets after $48 \mathrm{~h}$ incubation. Flow cytometry data is representative of $n=5$ experiments summarized in the graph. Error $=$ SEM. $* * * * p<0.0001$, one-way ANOVA with Tukey's correction.

complex rapidly sequestering amyloid seeds to render large populations of shorter fibrils, thus depleting the available seeding population to perform elongation. Interestingly, however, the shift in fibril persistence length induced by stars versus arms varied greatly; stars induced softer fibrils, whereas those generated in the presence of arms were notably stiffer. The capacity of PHEA to remodel IAPP amyloids was also assessed after coincubation for $24 \mathrm{~h}$ and demonstrated a similar trend. Amyloids were reduced in persistence length upon exposure to PHEA stars with the most notable effect seen as soft, limp fibrils "bundling" at PHEA:IAPP 1:5. Conversely, negligible amyloid remodeling was observed in the presence of PHEA arms. These observations could be attributed to the differences in morphology and surface physicochemical properties of the stars and arms.

Stelliform IAPP Amyloids Are Cytoprotective in Vitro and ex Vivo. IAPP-mediated cytotoxicity was assessed in an insulin-producing pancreatic $\beta$-cell line over a $24 \mathrm{~h}$ period (Figure 5A) and ex vivo in mouse islets after $48 \mathrm{~h}$ (Figure 5B). PHEA stars were completely biocompatible at all concentrations tested. In vitro, IAPP alone typically began to induce cytotoxicity at $\sim 6 \mathrm{~h}$ post-treatment with cell death progressing exponentially up until the $20-24 \mathrm{~h}$ mark to an end point toxicity value of $38 \%$. When incubated with IAPP at $1: 25$ and 1:125 ratios, PHEA stars delayed the progression of IAPP toxicity by $\sim 2 \mathrm{~h}$ and reduced IAPP-mediated toxicity overall compared to that of the IAPP control. However, with PHEA stars:IAPP 1:5, cells were 94\% viable after $24 \mathrm{~h}$, and low levels of cytotoxicity were only observed more than $15 \mathrm{~h}$ post incubation. Per their aromatic structures, ${ }^{31}$ PHEA arms successfully mitigated IAPP cytotoxicity at all concentrations tested (Figure S2). The cytoprotective capacity of PHEA stars at a 1:5 ratio to IAPP was also seen ex vivo, where mouse islets treated with IAPP in the presence of the highest concentration of PHEA stars $(\sim 8 \%$ relative cell death) demonstrated a significant reduction in toxicity compared to that of IAPP alone (64\%) after $48 \mathrm{~h}$ treatment.

The near-complete mitigation in IAPP-mediated toxicity observed both in vitro and ex vivo when IAPP was incubated with PHEA stars correlated with stelliform amyloid formation at the PHEA:IAPP ratio of 1:5, as observed in Figure 4A. Likely the key to the cytoprotective nature of stelliform amyloids lies first in their mechanism of formation and additionally in terms of the structure itself. First, oligomeric and low-order protofibrillar species formed as intermediates during IAPP amyloidogenesis are widely considered responsible for the majority of IAPP-mediated cytotoxicity ${ }^{3}$ with far less toxicity attributed to amyloid fibrils. ${ }^{28}$ Seeding of IAPP oligomers to the plasma membrane of pancreatic $\beta$-cells resulted in destabilization of the lipid membrane $e^{47}$ and cell death through "lipid stripping". 48 Concordantly, rapid sequestering of toxic loworder IAPP species through the formation of stelliform amyloids mediated by PHEA stars would reduce the local population of toxic species around the cell membrane.

Lastly, it has also been purported that the cytotoxicity of amyloid fibrils is mediated through partitioning of the hydrophobic, stiff fibrils into the cell membrane, leading to disruption of the membrane and production of radical oxygen species. ${ }^{47,49,50}$ The structure of stelliform amyloids, with a compact core and vastly reduced persistence and contour 

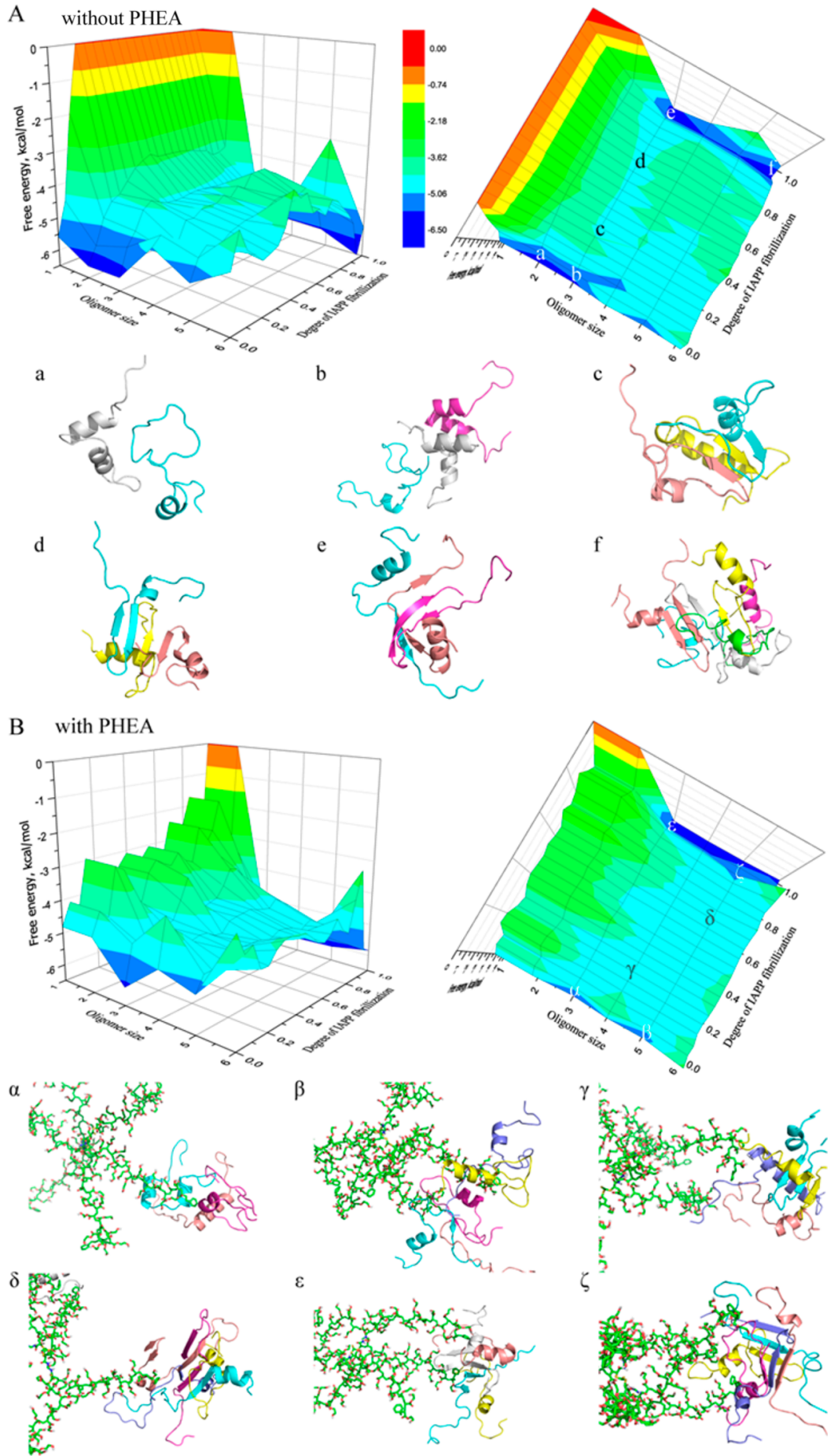

Figure 6. Aggregation free energy landscapes of IAPP without (A) and with (B) PHEA. Three-dimensional potentials of mean force (PMFs) with respect to IAPP oligomer size and degree of fibrillization were used to derive the free energy landscapes in front and top views. Snapshot structures with IAPP in cartoon and PHEA polymers in stick are shown to illustrate the basins and saddles of the energy landscapes.

lengths of radiating fibrils, would be unable to effectively partition into the lipid bilayer ${ }^{51}$ and would also readily form a protein corona ${ }^{52,53}$ within the extracellular milieu through electrostatic and hydrophobic interactions, further limiting any amyloid contact with cellular membranes. Importantly, we observed complete protection from IAPP-induced cell death in primary mouse islets treated with PHEA stars at a 1:5 molar ratio.

In Silico Study of the PHEA Polymers and Their Effects on IAPP Aggregation. To complement the experimental findings, we examined the structural properties of model PHEA polymers by all-atom DMD simulations ${ }^{35}$ (see Experimental Methods, ESI). We first studied 2-arm PHEA polymers (Figure S4A) with different degrees of polymerization (DP) and computed their corresponding radius of gyration $\left(R_{\mathrm{g}}\right)$ values (Figure S4D). The data revealed an approximately linear dependence of $R_{\mathrm{g}}$ on DP (up to $\sim 40$, Figure S4D), suggesting that the PHEA stars were rather rigid. The autocorrelation analysis of the polymer dynamics in simulations resulted in an estimated Kuhn length of $~ 36$ repeats (Figure 
S4E), which confirmed the rigidity of the PHEA stars. To evaluate the structure and dynamics of PHEA stars, we studied an 8-arm PHEA model with molecular compositions resembling the experimental data (Figure S4C) in all-atom DMD simulations. A rapid equilibration in terms of $R_{\mathrm{g}}$ and ellipticity was observed (Figure S4F). The average $R_{\mathrm{g}}$ of the 8arm polymer was $\sim 4.5 \mathrm{~nm}$, consistent with the experimentally measured hydrodynamic radii (Figure 1C). The high ellipticity value (close to 1 ) suggests that the 8 -arm PHEA adopted a nonspherical conformation as illustrated by a typical snapshot 3D structure (e.g., the inset of Figure S4F). Because of the high rigidity, the interactions between different arms were found minimal beyond the covalent cross-links. Therefore, the allatom DMD simulations revealed a different morphology of the PHEA stars from that of PAMAM dendrimers, which feature a micellar structure with a porous interior for encapsulating small molecules $^{54}$ and IAPP peptides. ${ }^{26}$

To provide molecular insight into IAPP-PHEA binding and its effect on IAPP self-association, we performed DMD simulations on two sets of molecular systems with one containing six IAPP peptides along with a 6-arm PHEA polymer (Figure S4B) and another of six peptides alone as the control (see Experimental Methods in the ESI). We first monitored the size of the largest IAPP aggregates as a function of the simulation time and noted that the presence of PHEA indeed accelerated the self-association clusters in silico (Figure $\mathrm{S} 5 \mathrm{~A}$ ). On the basis of the last $25 \mathrm{~ns}$ of the simulations where the largest IAPP aggregates were formed, the binding probability of each IAPP residue with PHEA indicated that both polar and nonpolar residues of IAPP could bind PHEA, though hydrophobic and aromatic residues showed a slightly higher binding propensity (Figure S5B). As a result, the generally nonspecific attraction between IAPP and PHEA led to the accumulation of peptides on PHEA arms, and the increased local peptide concentration accelerated the aggregation of IAPP consistently with a previous coarse-grained computational study. ${ }^{55}$ We also examined the secondary structure of IAPPs and their binding with PHEA along the simulation trajectories (e.g., one of the independent simulations shown in Figure S6), where a general trend of correlation between IAPP-PHEA binding and $\beta$-sheet formation in IAPP aggregates was evident. Comparison-average secondary structure contents of the last 25 ns between simulations with and without PHEA (Figure S5C and D) suggest that the PHEA binding did not significantly affect the structures of the aggregates other than accelerated IAPP self-association (Figure S4A).

Next, the kinetics of $\beta$-sheet formation were analyzed for simulations of IAPPs with and without PHEA. The total number of IAPP residues in the $\beta$-sheet conformation followed sigmoidal-like kinetics (i.e., a lag phase followed by rapid growth/elongation and saturation as in Figure S7A) resembling experimentally observed aggregation kinetics. As expected for a nucleation-dependent process, each of the independent simulations rendered different lag times and elongation rates (see the fitting analysis in the Experimental Methods). The presence of PHEA significantly reduced the aggregation lag times (Figure S7B) and broadened the distribution of the elongation rates (Figure S7C), further suggesting that PHEA binding accelerated the nucleation of $\beta$-sheet aggregates and induced heterogeneity in $\beta$-sheet elongation, respectively. Additionally, the potential of mean force (PMF; i.e., the effective aggregate free energy landscape in Figure 6) was computed with respect to the size of IAPP oligomers, $n_{\text {oligomer }}$ and the degree of IAPP fibrillization, $Q_{\text {fibrillization }}$ (for details, see Experimental Methods in the ESI). Two major basins, one corresponding to IAPP monomers and oligomers with little $\beta$ sheets (e.g., highlighted as $a, b$ in Figure $6 \mathrm{~A}$ and $\alpha, \beta$ in Figure $6 \mathrm{~B})$ and the other denoting IAPP aggregates with high amounts of $\beta$-sheets (e.g., $e, f$ in Figure $6 \mathrm{~A}$ and $\varepsilon, \zeta$ in Figure 6B), could be observed in both IAPP aggregation free energy landscapes with and without PHEA stars. The saddles connecting the two basins corresponded to the aggregation pathways and intermediates (e.g., $c, d$ in Figure $6 \mathrm{~A}$ and $\gamma, \delta$ in Figure 6B). The presence of the PHEA star rendered the non- $\beta$-sheet basin shallower and the saddle broader (i.e., more pathways/routes toward final $\beta$-rich aggregates in Figure $6 \mathrm{~B}$ ), which accounted for the reduced aggregation lag times (Figure S7B) and heterogeneity in $\beta$-sheet elongation rates (Figure S7C).

\section{CONCLUSIONS}

Inspired by the mechanism of Pmel17 amyloidogenesis, we have developed and established that a polymeric star nanoparticle, PHEA, is capable of mitigating IAPP-mediated toxicity both in vitro and ex vivo through PHEA-mediated promotion of IAPP aggregation and formation of a unique "stelliform amyloid" morphology. Unlike the porous PAMAM-OH dendrimers, which inhibited both IAPP aggregation and toxicity through peptide sequestration, ${ }^{26}$ the possession of high rigidity, long arm length, and rich aromatic moieties of PHEA stars facilitated rapid deposition and fibrillization of IAPP monomers into amyloid fibrils. Subsequently, this amyloid structure elicited significantly reduced toxicity in a pancreatic $\beta$-cell line and in mouse islets when compared to the long, semiflexible fibrils typically formed by IAPP. In light of the observation that both PHEA arms and stars elevated IAPP aggregation while mitigating IAPP toxicity, whereas dendrimers and hyperbranched polymers have been predominantly shown in the literature to inhibit amyloid protein aggregation, ${ }^{11-18,21-26}$ it is plausible to attribute the observed phenomenon chiefly to the structure and physicochemical properties of the PHEA. Nonetheless, the shape/morphology of the PHEA stars was likely a contributing factor in the IAPP-PHEA interaction, as reflected by the difference in IAPP fibril stiffness associated with PHEA stars versus arms. Shortening of the oligomer lifetime through amyloid aggregation promotion represents a potential strategy to be explored within the larger context of amyloid research, ${ }^{56}$ although implementation of such a strategy in vivo remains a challenge given the stochastic nature of secondary nucleation of amyloid proteins. This study has shed new light on the IAPP structure-toxicity relationship and presents an alternative blueprint for the design of polymeric nanomedicines against amyloidogenesis.

\section{ASSOCIATED CONTENT}

\section{Supporting Information}

The Supporting Information is available free of charge on the ACS Publications website at DOI: 10.1021/acs.biomac.7b01301.

Details of star polymer characterization, PHEA arms analysis, CD spectroscopy, and DMD simulations (PDF)

\section{AUTHOR INFORMATION}

\section{Corresponding Authors}

*E-mail: john.f.quinn@monash.edu.

*E-mail: thomas.p.davis@monash.edu. 
*E-mail: pu-chun.ke@monash.edu.

\section{ORCID}

Michael R. Whittaker: 0000-0001-5706-3932

Esteban N. Gurzov: 0000-0003-4642-0273

Feng Ding: 0000-0003-1850-6336

John F. Quinn: 0000-0002-4593-1170

Thomas P. Davis: 0000-0003-2581-4986

$\mathrm{Pu}$ Chun Ke: 0000-0003-2134-0859

\section{Author Contributions}

P.C.K. and T.P.D. conceived the project. M.L., M.R.W., and J.F.Q. designed and performed PHEA synthesis and characterization. E.H.P. performed TEM, ThT, CD, and in vitro viability assays and analysis. M.W., M.A.S., and A.K. performed TEM and $\mathrm{CD}$ data analysis. E.N.G. and W.J.S. conducted the ex vivo viability assay and analysis. X.G., B.W., and F.D. performed DMD simulations and data analysis. E.H.P., P.C.K., J.F.Q., and X.G. wrote the paper. All authors discussed the data and agreed on the manuscript.

\section{Notes}

The authors declare no competing financial interest.

\section{ACKNOWLEDGMENTS}

This work was supported by ARC Project CE140100036 (T.P.D.), NSF CAREER CBET-1553945 (F.D.), NIH MIRA R35GM119691 (F.D.), NHMRC project grant APP1071350 (E.N.G.), and the Monash Institute of Pharmaceutical Sciences (P.C.K.). T.P.D. is thankful for the award of an Australian Laureate Fellowship from the ARC. J.F.Q. acknowledges receipt of a Future Fellowship from the ARC. E.H.P. acknowledges the support of an Australian Government Research Training Program scholarship. E.N.G. is supported by a Juvenile Diabetes Research Foundation (JDRF) fellowship.

\section{REFERENCES}

(1) Mendis, S. Global status report on noncommunicable diseases 2014; World Health Organization: Geneva, Switzerland, 2014.

(2) Kahn, S. E. The Importance of the $\beta$-Cell in the Pathogenesis of Type 2 Diabetes Mellitus. Am. J. Med. 2000, 108, 2S-8S.

(3) Pillay, K.; Govender, P. Amylin Uncovered: A Review on the Polypeptide Responsible for Type II Diabetes. BioMed Res. Int. 2013, 2013, 1 .

(4) Despa, S.; Margulies, K. B.; Chen, L.; Knowlton, A. A.; Havel, P. J.; Taegtmeyer, H.; Bers, D. M.; Despa, F. Hyperamylinemia Contributes to Cardiac Dysfunction in Obesity and Diabetes: A Study in Humans and Rats. Circ. Res. 2012, 110, 598-608.

(5) Srodulski, S.; Sharma, S.; Bachstetter, A. B.; Brelsford, J. M.; Pascual, C.; Xie, X. S.; Saatman, K. E.; Van Eldik, L. J.; Despa, F. Neuroinflammation and neurologic deficits in diabetes linked to brain accumulation of amylin. Mol. Neurodegener. 2014, 9, 30.

(6) Wang, M.; Käkinen, A.; Pilkington, E. H.; Davis, T. P.; Ke, P. C. Differential Effects of Silver and Iron Oxide Nanoparticles on IAPP Aggregation and Toxicity. Biomater. Sci. 2017, 5, 485-493.

(7) Govindan, P. N.; Gurzov, E. N.; Chen, P.; Pilkington, E. H.; Stanley, W. J.; Litwak, S. A.; Davis, T. P.; Ke, P. C.; Ding, F. Graphene Oxide Inhibits hIAPP Amyloid Fibrillation and Toxicity in InsulinProducing NIT-1 Cells. Phys. Chem. Chem. Phys. 2016, 18, 94-100.

(8) Wang, B.; Pilkington, E. H.; Sun, Y.; Davis, T. P.; Ke, P. C.; Ding, F. Modulating protein amyloid aggregation with nanomaterials. Environ. Sci.: Nano 2017, 4, 1772-1783.

(9) Ke, P. C.; Sani, M.-A.; Ding, F.; Käkinen, A.; Javed, I.; Separovic, F.; Davis, T. P.; Mezzenga, R. Implications of peptide assemblies in amyloid diseases. Chem. Soc. Rev. 2017, DOI: 10.1039/C7CS00372B.

(10) Cabaleiro-Lago, C.; Quinlan-Pluck, F.; Lynch, I.; Lindman, S.; Minogue, A. M.; Thulin, E.; Walsh, D. M.; Dawson, K. A.; Linse, S.
Inhibition of Amyloid $\beta$ Protein Fibrillation by Polymeric Nanoparticles. J. Am. Chem. Soc. 2008, 130, 15437-15443.

(11) Breydo, L.; Newland, B.; Zhang, H.; Rosser, A.; Werner, C.; Uversky, V. N.; Wang, W. A hyperbranched dopamine-containing PEG-based polymer for the inhibition of $\alpha$-synuclein fibrillation. Biochem. Biophys. Res. Commun. 2016, 469, 830-835.

(12) Chowdhury, S. R.; Agarwal, M.; Meher, N.; Muthuraj, B.; Iyer, P. K. Modulation of Amyloid Aggregates into Nontoxic Coaggregates by Hydroxyquinoline Appended Polyfluorene. ACS Appl. Mater. Interfaces 2016, 8, 13309-13319.

(13) Debnath, K.; Shekhar, S.; Kumar, V.; Jana, N. R.; Jana, N. R. Efficient Inhibition of Protein Aggregation, Disintegration of Aggregates, and Lowering of Cytotoxicity by Green Tea PolyphenolBased Self-Assembled Polymer Nanoparticles. ACS Appl. Mater. Interfaces 2016, 8, 20309-20318.

(14) McCarthy, J. M.; Appelhans, D.; Tatzelt, J.; Rogers, S. M. Nanomedicine for prion disease treatment. Prion 2013, 7, 198-202.

(15) Sorokina, S. A.; Stroylova, Y. Y.; Shifrina, Z. B.; Muronetz, V. I. Disruption of Amyloid Prion Protein Aggregates by Cationic Pyridylphenylene Dendrimers. Macromol. Biosci. 2016, 16, 266-275.

(16) Fischer, M.; Appelhans, D.; Schwarz, S.; Klajnert, B.; Bryszewska, M.; Voit, B.; Rogers, M. Influence of Surface Functionality of Poly(propylene imine) Dendrimers on Protease Resistance and Propagation of the Scrapie Prion Protein. Biomacromolecules 2010, 11, 1314-1325.

(17) Klajnert, B.; Appelhans, D.; Komber, H.; Morgner, N.; Schwarz, S.; Richter, S.; Brutschy, B.; Ionov, M.; Tonkikh, A. K.; Bryszewska, M.; Voit, B. The Influence of Densely Organized Maltose Shells on the Biological Properties of Poly(propylene imine) Dendrimers: New Effects Dependent on Hydrogen Bonding. Chem. - Eur. J. 2008, 14, 7030-7041.

(18) Solassol, J.; Crozet, C.; Perrier, V.; Leclaire, J.; Béranger, F.; Caminade, A.-M.; Meunier, B.; Dormont, D.; Majoral, J.-P.; Lehmann, $\mathrm{S}$. Cationic phosphorus-containing dendrimers reduce prion replication both in cell culture and in mice infected with scrapie. J. Gen. Virol. 2004, 85, 1791-1799.

(19) Supattapone, S.; Nguyen, H.-O. B.; Cohen, F. E.; Prusiner, S. B.; Scott, M. R. Elimination of prions by branched polyamines and implications for therapeutics. Proc. Natl. Acad. Sci. U. S. A. 1999, 96, 14529-14534.

(20) Supattapone, S.; Wille, H.; Uyechi, L.; Safar, J.; Tremblay, P.; Szoka, F. C.; Cohen, F. E.; Prusiner, S. B.; Scott, M. R. Branched Polyamines Cure Prion-Infected Neuroblasoma Cells. J. Virol. 2001, $75,3453-3461$.

(21) Benseny-Cases, N.; Klementieva, O.; Cladera, J. Dendrimers antiamyloidogenic potential in neurodegenerative diseases. New J. Chem. 2012, 36, 211-216.

(22) Klementieva, O.; Aso, E.; Filippini, D.; Benseny-Cases, N.; Carmona, M.; Juvés, S.; Appelhans, D.; Cladera, J.; Ferrer, I. Effect of Poly(propylene imine) Glycodendrimers on $\beta$-Amyloid Aggregation in Vitro and in APP/PS1 Transgenic Mice, as a Model of Brain Amyloid Deposition and Alzheimer's Disease. Biomacromolecules 2013, 14, $3570-3580$.

(23) Neelov, I. M.; Janaszewska, A.; Klajnert, B.; Bryszewska, M.; Makova, N. Z.; Hicks, D.; Pearson, H. A.; Vlaslov, G. P.; Ilyash, M. Y.; Dubrovskaya, N. M.; Tumanova, N. L.; Zhuravin, I. A.; Turner, A. J.; Nalivaeva, N. N. Molecular Properties of Lysine Dendrimers and their Interactions with A $\beta$-Peptides and Neuronal Cells. Curr. Med. Chem. 2013, 20, 134-143.

(24) Nguyen, P. T.; Sharma, R.; Rej, R.; De Carufel, C. A.; Roy, R.; Bourgault, S. Low generation anionic dendrimers modulate islet amyloid polypeptide self-assembly and inhibit pancreatic $\beta$-cell toxicity. RSC Adv. 2016, 6, 76360-76369.

(25) Nowacka, O.; Shcharbin, D.; Klajnert-Maculewicz, B.; Bryszewska, M. Stabilizing effect of small concentrations of PAMAM dendrimers at the insulin aggregation. Colloids Surf., B 2014, 116, $757-760$.

(26) Gurzov, E. N.; Wang, B.; Pilkington, E. H.; Chen, P.; Käkinen, A.; Stanley, W. J.; Litwak, S. A.; Hanssen, E. G.; Davis, T. P.; Ding, F.; 
Ke, P. C. Inhibition of hIAPP Amyloid Aggregation and Pancreatic $\beta$ Cell Toxicity by OH-Terminated PAMAM Dendrimer. Small 2016, $12,1615-1626$.

(27) Fowler, D. M.; Koulov, A. V.; Alory-Jost, C.; Marks, M. S.; Balch, W. E.; Kelly, J. W. Functional Amyloid Formation within Mammalian Tissue. PLoS Biol. 2006, 4, 0100-0107.

(28) Cheng, I. H.; Scearce-Levie, K.; Legleiter, J.; Palop, J. J.; Gerstein, H.; Bien-Ly, N.; Puoliväli, J.; Lesné, S.; Ashe, K. H.; Muchowski, P. J.; Mucke, L. Accelerating Amyloid- $\beta$ Fibrillization Reduces Oligomer Levels and Functional Deficits in Alzheimer Disease Mouse Models. J. Biol. Chem. 2007, 282, 23818-23828.

(29) Chen, J.; Armstrong, A. H.; Koehler, A. N.; Hecht, M. H. Small Molecule Microarrays Enable the Discovery of Compounds that Bind the Alzheimer's A $\beta$ Peptide and Reduce its Cytotoxicity. J. Am. Chem. Soc. 2010, 132, 17015-17022.

(30) Bieschke, J.; Herbst, M.; Wiglenda, M.; Friedrich, R. P.; Boeddrich, A.; Schiele, F.; Kleckers, D.; del Amo, J. M. L.; Grüning, B. A.; Wang, Q.; Schmidt, M. R.; Lurz, R.; Anwyl, R.; Schnoegl, S.; Fändrich, M.; Frank, R. F.; Reif, B.; Günther, S.; Walsh, D. M.; Wanker, E. E. Small-molecule conversion of toxic oligomers to nontoxic $\beta$-sheet-rich amyloid fibrils. Nat. Chem. Biol. 2011, 8, 93101.

(31) Barrajón-Catalán, E.; Herranz-López, M.; Joven, J.; SeguraCarretero, A.; Alonso-Villaverde, C.; Menéndez, J. A.; Micol, V. Molecular Promiscuity of Plant Polyphenols in the Management of Age-Related Diseases: Far Beyond Their Antioxidant Properties. In Oxidative Stress and Inflammation in Non-communicable Diseases Molecular Mechanisms and Perspectives in Therapeutics; Camps, J., Ed.; Springer International: Switzerland, 2014; pp 141-159.

(32) Ren, M.; McKenzie, T. G.; Fu, Q.; Wong, E. H. H.; Xu, J.; An, Z.; Shanmugam, S.; Davis, T. P.; Boyer, C.; Qiao, G. G. Star Polymers. Chem. Rev. 2016, 116, 6743-6836.

(33) Ferreira, J.; Syrett, J.; Whittaker, M. R.; Haddleton, D. M.; Davis, T. P.; Boyer, C. Optimizing the generation of narrow polydispersity 'arm-first' star polymers made using RAFT polymerization. Polym. Chem. 2011, 2, 1671-1677.

(34) Hu, J.; Qiao, R.; Whittaker, M. R.; Quinn, J. F.; Davis, T. P. Synthesis of Star Polymers by RAFT Polymerization as Versatile Nanoparticles for Biomedical Applications. Aust. J. Chem. 2017, DOI: $10.1071 / \mathrm{CH} 17391$.

(35) Ding, F.; Tsao, D.; Nie, H.; Dokholyan, N. V. Ab initio folding of proteins with all-atom discrete molecular dynamics. Structure 2008, 16, 1010-1018.

(36) Usov, I.; Mezzenga, R. FiberApp: An Open-Source Software for Tracking and Analyzing Polymers, Filaments, Biomacromolecules, and Fibrous Objects. Macromolecules 2015, 48, 1269-1280.

(37) Adamcik, J.; Jung, J.-M.; Flakowski, J.; De Los Rios, P.; Dietler, G.; Mezzenga, R. Understanding amyloid aggregation by statistical analysis of atomic force microscopy images. Nat. Nanotechnol. 2010, 5, $423-428$.

(38) Stanley, W. J.; Litwak, S. A.; Quah, H. S.; Tan, S. M.; Kay, T. W.; Tiganis, T.; de Haan, J. B.; Thomas, H. E.; Gurzov, E. N. Inactivation of Protein Tyrosine Phosphatases Enhances Interferon Signaling in Pancreatic Islets. Diabetes 2015, 64, 2489-2496.

(39) Hanwell, M. D.; Curtis, D. E.; Lonie, D. C.; Vandermeersch, T.; Zurek, E.; Hutchison, G. R. Avogadro: an advanced semantic chemical editor, visualization, and analysis platform. J. Cheminf. 2012, 4, 17.

(40) Halgren, T. A. MMFF VI. MMFF94s option for energy minimization studies. J. Comput. Chem. 1999, 20, 720-729.

(41) Yin, S.; Biedermannova, L.; Vondrasek, J.; Dokholyan, N. V. MedusaScore: An Accurate Force-Field Based Scoring Function for Virtual Drug Screening. J. Chem. Inf. Model. 2008, 48, 1656-1662.

(42) Ding, F.; Dokholyan, N. Emergence of Protein Fold Families through Rational Design. PLoS Comput. Biol. 2006, 2, e85.

(43) Ding, F.; Dokholyan, N. Incorporating Backbone Flexibility in MedusaDock Improves Ligand-Binding Pose Prediction in the CSAR2011 Docking Benchmark. J. Chem. Inf. Model. 2013, 53, 1871-1879.
(44) Govindan, P. N.; Jemec, D. B.; Ding, F. CSAR Benchmark of Flexible MedusaDock in Affinity Prediction and Nativelike Binding Pose Selection. J. Chem. Inf. Model. 2016, 56, 1042-1052.

(45) Jean, L.; Lee, C. F.; Hodder, P.; Hawkins, N.; Vaux, D. J. Dynamics of the formation of a hydrogel by a pathogenic amyloid peptide: islet amyloid polypeptide. Sci. Rep. 2016, 6, 32124.

(46) Govindan, P. N.; Käkinen, A.; Pilkington, E. H.; Davis, T. P.; Ke, P. C.; Ding, F. Stabilizing Off-pathway Oligomers by Polyphenol Nanoassemblies for IAPP Aggregation Inhibition. Sci. Rep. 2016, 6, 19463.

(47) Pilkington, E. H.; Gurzov, E. N.; Käkinen, A.; Litwak, S. A.; Stanley, W. J.; Davis, T. P.; Ke, P. C. Pancreatic $\beta$-Cell Membrane Fluidity and Toxicity Induced by Human Islet Amyloid Polypeptide Species. Sci. Rep. 2016, 6, 21274.

(48) Sparr, E.; Engel, M. F. M.; Sakharov, D. V.; Sprong, M.; Jacobs, J.; de Kruifff, B.; Höppener, J. W. M.; Killian, J. A. Islet amyloid polypeptide-induced membrane leakage involves uptake of lipids by forming amyloid fibres. FEBS Lett. 2004, 577, 117-120.

(49) Huang, B.; He, J.; Ren, J.; Yan, X.-Y.; Zeng, C.-M. Cellular Membrane Disruption by Amyloid Fibrils Involved Intermolecular Disulfide Cross-Linking. Biochemistry 2009, 48, 5794-5800.

(50) Friedrich, R. P.; Tepper, K.; Rönicke, R.; Soom, M.; Westermann, M.; Reymann, K.; Kaether, C.; Fändrich, M. Mechanism of amyloid plaque formation suggests an intracellular basis of $\mathrm{A} \beta$ pathogenicity. Proc. Natl. Acad. Sci. U. S. A. 2010, 107, 1942-1947.

(51) Klementieva, O.; Benseny-Cases, N.; Gella, A.; Appelhans, D.; Voit, B.; Cladera, J. Dense Shell Glycodendrimers as Potential Nontoxic Anti-amyloidogenic Agents in Alzheimer's Disease. AmyloidDendrimer Aggregates Morphology and Cell Toxicity. Biomacromolecules 2011, 12, 3903-3909.

(52) Cedervall, T.; Lynch, I.; Lindman, S.; Berggård, T.; Thulin, E.; Nilsson, H.; Dawson, K. A.; Linse, S. Understanding the nanoparticleprotein corona using methods to quantify exchange rates and affinities of proteins for nanoparticles. Proc. Natl. Acad. Sci. U. S. A. 2007, 104, 2050-2055.

(53) Pilkington, E. H.; Xing, Y.; Wang, B.; Käkinen, A.; Wang, M.; Davis, T. P.; Ding, F.; Ke, P. C. Effects of Protein Corona on IAPP Amyloid Aggregation, Fibril Remodelling, and Cytotoxicity. Sci. Rep. 2017, 7, 2455.

(54) Wang, B.; Geitner, N. K.; Davis, T. P.; Ke, P. C.; Ladner, D. L.; Ding, F. Deviation from the Unimolecular Micelle Paradigm of PAMAM Dendrimers Induced by Strong Interligand Interactions. J. Phys. Chem. C 2015, 119, 19475-19484.

(55) Radic, S.; Davis, T. P.; Ke, P. C.; Ding, F. Contrasting effects of nanoparticle-protein attraction on amyloid aggregation. RSC Adv. 2015, 5, 105489-105498.

(56) Peterson, S. A.; Klabunde, T.; Lashuel, H. A.; Purkey, H.; Sacchettini, J. C.; Kelly, J. W. Inhibiting transthyretin conformational changes that lead to amyloid fibril formation. Proc. Natl. Acad. Sci. U.S. A. 1998, 95, 12956-12960. 